\title{
Semiactive Control for Floating Offshore Wind Turbines Subject to Aero-hydro Dynamic Loads
}

\author{
N. Luo ${ }^{1}$, C.L. Bottasso ${ }^{2}$, H.R. Karimi ${ }^{3}$, M. Zapateiro ${ }^{4}$ \\ ${ }^{\mathbf{1}}$ Institute of Informatics and Applications, University of Girona, Girona, Spain. \\ +34972418 888, ningsu.luo@udg.edu \\ 2 Dipartimento di Ingegneria Aerospaziale, Politecnico di Milano, Milano, Italy. \\ +39-02-2399-8315, carlo.bottasso@ polimi.it \\ ${ }^{3}$ Department of Engineering, Faculty of Engineering and Science, University of Agder, Grimstad, Norway. \\ +47-3725-3259, hamid.r.karimi@uia.no \\ ${ }^{4}$ Department of Applied Mathematics III, Universitat Politècnica de Catalunya, Barcelona, Spain. \\ +34934 137 316, mauricio.zapateiro@upc.edu
}

\begin{abstract}
Wind and wave dynamic loads might cause undesirable vibrations that affect the structure integrity and system performance of floating offshore wind turbines. This paper addresses the problem of dynamic load mitigation by using semiactive control techniques with the tuned liquid column dampers placed on the turbine's tower. The control law is formulated based on the mixed $\mathrm{H}_{2} / \mathrm{H}_{\infty}$ methods for ensuring the system stability and reliability. Furthermore, the proposed controller only uses output feedback so as to avoid the dependence on the knowledge of the states of the system.
\end{abstract}

\section{Key words}

Floating wind turbines, offshore wind energy, semiactive control, mitigation of dynamic loads and vibrations, liquid column dampers.

\section{Introduction}

In recent years, offshore wind energy becomes one of the fastest growing powers in the field of renewable energy [1]-[2]. Although the installation and operation cost of offshore wind power is still more expensive than that of onshore wind power, an offshore wind farm situated sufficiently far away from the coast (e.g. $>25 \mathrm{~km}$ ) can generate more wind power and will have a longer operation life since the winds are stronger and more consistent than those on or near the coast. It can also avoid some major problems of the traditional wind farms like the visual and noise impacts and potential damage to wildlife. From the technical point of view, it is difficult to anchor the wind turbines directly on the seabed in the areas where the water depth is greater than 50 meters. Thus, new constructive solutions based on floating support substructures are proposed, which need a highly complex technological innovation. In June of 2009, the first floating offshore wind turbine of the world was installed by Statoil-Hydro and Siemens off the coast of Karmøy, Norway.

Wind turbines are highly flexible machines operating in stochastic environments. One of the main challenges is to reduce the fatigues of a floating offshore wind turbine so as to guarantee its proper functioning under the constraints imposed by the floating support substructures subject to a greater range of motion than that of the conventional fixed ones. Due to the coupling effects of the wind and wave dynamics, we should consider the effect of the floating support substructure motion on the strength of the blades and shafting, and the inertia force induced by the combined rotational, translational and angular motion of the blades. Thus, an exhaustive study should be done to model the wind turbine environments and obtain their response to environmental forces during operation. The application of advanced control strategies to wind turbines is crucial for maximizing the energy captured from the wind [3] and minimizing the dynamic loads of these machines for the extension of their fatigue life [4]-[5].

This paper addresses the problem of designing semiactive controllers to mitigate the dynamic wind and wave loads on floating offshore wind turbines, which might cause undesirable vibrations that affect the structure integrity and system performance. The output feedback control strategy is proposed to avoid the dependence on the knowledge of the states of the system. The mixed $\mathrm{H}_{2} / \mathrm{H}_{\infty}$ 
control technique is used for formulating the semiactive control law, which will be implemented using a TLCD (tuned liquid column damper). Numerical simulation is done to verify the obtained results.

\section{Vibration Mitigation using Tuned Liquid Column Damper (TLCD)}

Floating wind turbine modeling can be broken into the following distinct but related areas: aerodynamics, hydrodynamics, turbulent inflow, foundation dynamics and structural dynamics. Modeling aerodynamics is critical for predicting how the varying winds are transformed into power and the loads that affect wind turbine performance [6]-[7]. The wind is by nature a highly stochastic process involving many different length and time scales. International design standards have sought to quantify the wind inflow in terms of both extreme events and also smaller scale stochastic variability. In addition to the mean wind speed and turbulence levels, wind shear is another important variable for load production. In general, aerodynamic models tend to have the greatest uncertainty of all the modeling regimes, given the potential for nonlinear behavior. The prediction of hydrodynamic loads that affect the floating support substructures is an active research topic [8]. The hydrodynamics depend on the foundation system and water depth for the offshore turbine installation. Since wind turbines operating in this environment are floating, the substructure motions affect the incoming wave dynamics [9]-[10]. Consequently, the experience of onshore wind turbines cannot be applied directly to the development of floating wind turbines. In general, the fatigue loads govern most parts of the support substructure design [11]. For these loads, the effects of wind-wave directional distribution and misalignment, damping and associated dynamic amplification, play a dominant role. For floating wind turbines, the support substructures are considered compliant and have large motions. The dynamic responses of the floating wind turbines and support substructures are strongly coupled [12]-[13]. The floating structural dynamics depend on how the support substructure be stabilized by ballast, mooring lines or buoyancy [14]. The most important structural components of a wind turbine are the blades, drive train and tower, but we can also include the nacelle, pitch system, yaw drive and hub. For the more flexible elements of the system, such as the blades and tower, engineering codes typically use a modal representation of the deformed shape of the structure. The multibody dynamics representation [15][16] of the blades and tower and the multi-disciplinary optimization [17]-[18] can also be used, which allows for virtually unlimited degrees of freedom and easier coupling between them, but considerably slows the calculation time. The effect of support substructure motion on the strength of the blades and shafting is a key issue to be investigated for designing the wind turbine and support substructure [11]. The effect of greater motion, especially the inertia force induced by the combined rotational, translational and angular motion of the blades, needs to be precisely formulated [13].
The response of floating offshore wind turbines is strongly affected by the "wet" hydro-elastic part of the machine; i.e. the hydrodynamic loads on the submerged part of the tower give rise to hydro-elastic effects, due to the flexibility of the tower itself and/or the interaction with the mooring system for floating platforms. Clearly, such hydro-elastic phenomena couple with the "dry" aeroservo-elastic part of the machine, giving rise to a complex scenario with multiple interacting fields operating at similar bandwidths. The design of modern large and slender offshore wind turbines is based on the sophisticated knowledge of such phenomena; furthermore, control laws must be designed for the reduction of loads and vibrations on such systems, which is crucial for their safe and effective operation and for the extension of their fatigue life [5]. Yaw, torque and pitch control are the mode most often used in industry. Eventually, more active aerodynamic control devices or vibration control devices may also be placed on blades or tower, which will require additional design code and control system development. In order to mitigate the dynamic loads, it is generally accepted the need of allowing inelastic deformations in structures. A major difficulty in the control of floating offshore wind turbine is the presence of stochastic aerodynamic load (e.g. turbulent wind) and hydrodynamic load (e.g. wave current).

Among many control strategies, semiactive control technology is particularly useful for reducing the capital and maintenance costs, eliminating the external energy dependence and increasing the reliability and robustness of the system [19]. The specific characteristics of floating offshore wind turbines require new methodologies and tools for modeling and design of control systems and some innovative control devices for dynamic load mitigation [20]. One of the most visible and effective ways is to place a tuned liquid column damper (TLCD) on top of the structure. This was proposed by [21] and it consists in suppressing the wind-induced motion by dissipating the energy through the motion of the liquid mass through an orifice in a U-shaped tube [22]. The use of TLCDs in mitigating vibrations within civil engineering structures has also been extensively studied [23]-[25]. Yalla and Kareem [26] presented an approach to compute the optimum head loss coefficient for a given level of wind or seismic excitation in a single step without resorting to iterations. The stochastic performance of single-tuned liquid column dampers (STLCDs) for reducing seismic response of flexible structures is also investigated by Won et al. [27]. In parallel to the studies of multiple-tuned mass dampers and multiple-tuned liquid dampers, the performance of a MTLCD with distributed frequencies over a certain range around one particular natural frequency of a tall building in reducing its horizontal motion is also investigated by Chang et al. [28] and Gao et al. [29] for wind application. In [30], an experimental investigation on the performance of MTLCDs is presented for reducing torsional vibration of structures in comparison with STLCDs. A large structure model simulating its torsional vibration and several STLCDs and MTLCDs of different configurations are designed and constructed. 
The TLCD in its original form is a passive damper. With the addition of a controllable valve to the TLCD it turns into a semiactive damper. With a suitable control law, it is possible to adapt the orifice opening according to the structure response and loading conditions. To the best of the authors' knowledge, there are few works on feedback control of structures with TLCDs. Some of the techniques used are optimal control [31], on-off control and fuzzy logic [22]. In this work, our objective is to illustrate $H_{\infty}$ static output feedback design techniques for semiactive vibration control of offshore wind turbine towers with Tuned Liquid Column Dampers. Static output feedback is applied in many areas Recently, an output-feedback mixed $\mathrm{H}_{2} / \mathrm{H}_{\infty}$ controller has successfully been tested with other semiactive device, the MR damper and it is expected to provide satisfactory results in this case as well [32]-[33]. The main advantage of the static output feedback is the simplicity of its implementation and ability it provides for designing compensators of prescribed structure.

\section{Semiactive Controller Design}

Consider the schematic of the combined tower and liquid column damper with a controllable valve of Figure 1.

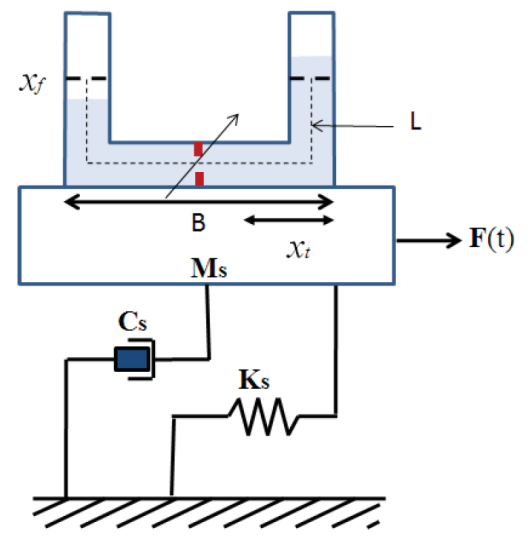

Fig. 1. Schematic of combined structure-LCD system.

The dynamics of this damper can be modeled as [21]:

$$
\rho A L \ddot{x}_{f}(t)+\frac{1}{2} \rho A \xi(t)\left|\dot{x}_{f}(t)\right| \dot{x}_{f}(t)+2 \rho A g x_{f}(t)=-\rho A B \ddot{x}_{t}(t)
$$

where $x_{f}(t)$ is the variation (displacement) in elevation of the liquid column, $x_{t}(t)$ is the displacement at the top of the tower, $\rho$ is the liquid density, $A$ is the cross-section area of the tube, $\mathrm{L}$ is the length of the liquid column, $\xi(t)$ is the head loss coefficient, $g$ is the gravitational acceleration and $B$ is the horizontal column length. The tower can be modeled as an $m$-degree of freedom system. The dynamics of the combined system is represented by the following equation:

$$
\begin{gathered}
{\left[\begin{array}{cc}
M_{s}+m_{f} I & \alpha m_{0} \\
\alpha m_{0}^{T} & m_{f}
\end{array}\right] \cdot\left[\begin{array}{l}
\ddot{x}_{s}(t) \\
\ddot{x}_{f}(t)
\end{array}\right]+\left[\begin{array}{cc}
C_{s} & 0 \\
0 & 0
\end{array}\right] \cdot\left[\begin{array}{l}
\dot{x}_{s}(t) \\
\dot{x}_{f}(t)
\end{array}\right]} \\
{\left[\begin{array}{cc}
K_{s} & 0 \\
0 & 0
\end{array}\right] \cdot\left[\begin{array}{l}
x_{s}(t) \\
x_{f}(t)
\end{array}\right]=\left[\begin{array}{c}
F(t) \\
0
\end{array}\right]+\left[\begin{array}{l}
0 \\
1
\end{array}\right] \cdot u(t)}
\end{gathered}
$$

where $x_{s}(t)$ is the displacement vector of the structure, $M_{s}$ is the mass matrix of the structure, $C_{s}$ is the damping coefficient matrix of the structure, $K_{s}$ is the stiffness matrix of the structure, $F(t)$ is the disturbance input vector. On the other hand, $m_{0}=\left[0,0, \ldots, m_{f}\right]^{\mathrm{T}}, m_{f}=\rho A L$ is the mass of the column liquid, $I$ is the identity matrix, $\alpha=$ $B / L$ is the horizontal length to column length ratio and $k_{f}=$ $2 \rho \mathrm{Ag}$ is associated to the stiffness of the liquid column. The constraint $\left|x_{f}(t)\right| \leq(L-B) / 2$ is applied to keep the water inside the vertical sections at all times. The control input $u$ is the damping force provided by the LCD and is related to the controllable valve in the following way:

$$
u(t)=-\frac{1}{2} \rho A \xi(t)\left|\dot{x}_{f}(t)\right| \dot{x}_{f}(t)
$$

where the head loss coefficient $\xi(t)$ is dependent on the valve opening and the valve conductance. Usually, valve suppliers provide the characteristic curves. The head loss is defined as

$$
h_{f}(t)=\xi(t) x_{f}^{2}(t) /(2 g)
$$

In this way, by manipulating the ratio of the valve opening, it is possible to vary the damping force of the LCD given by (3). Finally, the control force is regulated by varying the coefficient of head loss as an on-off control in accordance with the semiactive control strategy given as follows:

$$
\begin{array}{lll}
\xi(t)=\xi_{\max } & \text { if } & u(t) \dot{x}_{f}(t)<0 \\
\xi(t)=\xi_{\min } & \text { if } & u(t) \dot{x}_{f}(t) \geq 0
\end{array}
$$

where $\xi_{\text {min }}$ can be taken as zero because this corresponds to the fully opened valve. It can be expected that a small value of $\xi_{\max }$ will result in a lower level of response reduction.

The objective of the control design is to reduce the structure response when subject to disturbances such as strong winds and waves. The goal is to keep the structure response as small as possible with a low control effort. Furthermore, it is desirable that the amount of sensors necessary for control implementation is as minimal as possible. Accelerometers are the most widely used sensors because of practical implementation and reliability issues. In this research, an output-feedback $H_{\infty}$ control approach is proposed to solve the problem. The system (2) can be written in the standard state space form:

$$
\begin{gathered}
\dot{x}(t)=A x(t)+B u(t)+D w(t) \\
y(t)=C x(t)
\end{gathered}
$$

where

$$
A=\left[\begin{array}{cc}
0 & I \\
-M_{\text {aug }}^{-1}\left[\begin{array}{cc}
K_{s} & 0 \\
0 & K_{f}
\end{array}\right] & -M_{\text {aug }}^{-1}\left[\begin{array}{cc}
C_{s} & 0 \\
0 & 0
\end{array}\right]
\end{array}\right],
$$




$$
B=\left[\begin{array}{c}
0 \\
M_{\text {aug }}^{-1}\left[\begin{array}{l}
0 \\
1
\end{array}\right]
\end{array}\right], \quad D=\left[\begin{array}{c}
0 \\
M_{\text {aug }}^{-1}\left[\begin{array}{c}
I \\
0
\end{array}\right]
\end{array}\right],
$$

where

$$
M_{\text {aug }}:=\left[\begin{array}{cc}
M_{s}+m_{f} I & \alpha m_{0} \\
\alpha m_{0}^{T} & m_{f}
\end{array}\right]
$$

and a performance output $z(t)$ that satisfies

$$
\|z(t)\|^{2}=x^{T}(t) Q x(t)+R u^{2}(t)
$$

where $x=\left[x_{s}(t), x_{f}(t), \dot{x}_{s}(t), \dot{x}_{f}(t)\right]$ is the state vector, $u(t)$ is the control input (the damping force from the TLCD), $z(t)=\left[\lambda_{1} \ddot{x}_{s}(t), \lambda_{2} x_{s}(t)\right]$ is a vector of controlled signals (represented in this case by the weighted structure lumped masses accelerations and displacements), $w(t)$ is the disturbance input vector (due to wind and wave loadings) and $y(t)$ is the vector of available measurements (typically, accelerations).

The system under consideration is said to be bounded or attenuated by $\gamma$ if

$$
\sup _{w \in L_{2}, w \neq 0} \frac{\|z(t)\|_{2}^{2}}{\|w(t)\|_{2}^{2}} \leq \gamma^{2}
$$

in other word, the $H_{\infty}$ performance measure should satisfy

$$
J_{\infty}=\int_{0}^{\infty}\left(z^{T} z-\gamma^{2} w^{T} w\right) d t<0
$$

where $\gamma$ is a given positive scalar.

We can formulate the problem of controller design as follows: given the system (2) with a prescribed level of disturbance attenuation $\gamma>0$, find an $H_{\infty}$ output feedback control $u(t)=K y(t)$ where $K$ is the control gain to be determined such that:

1) The resulting closed-loop system is asymptotically stable,

2) Under zero initial conditions and for all non-zero $w \in L_{2}[0, \infty)$, the induced $L_{2}$ - norm of the operator from $w(t)$ to the performance output $z(t)$ is less than a positive scalar $\gamma$; i.e. $J_{\infty}<0$.

Assume that $Q \geq 0$ and $(A, \sqrt{Q})$ is detectable. Then, the system defined by (7)-(8) is output feedback stabilizable with $L_{2}$ - gain bounded by $\gamma$, if and only if:

1) $(A, B)$ is stabilizable and $(A, C)$ is detectable

2) There exist matrices $K^{*}$ and $L$ such that

$$
K^{*} C=R^{-1}\left(B^{T} P+L\right)
$$

where $P>0, P^{T}=P$ is a solution of

$$
P A+A^{T} P+Q+\frac{1}{\gamma^{2}} P D D^{T} P-P B R^{-1} B^{T} P+L^{T} R^{-1} L=0
$$

\section{Algorithm ( $H_{\infty}$ Static Output feedback Solution):}

1) Initialize: Set $n=0, L_{0}=0$, and select $\gamma, Q$ and $R$.

2) $n$th iteration: Solve for $P_{n}$ in

$$
P_{n} A+A^{T} P_{n}+Q+\frac{1}{\gamma^{2}} P_{n}\left(D D^{T}-B R^{-1} B^{T}\right) P_{n}+L_{n}^{T} R^{-1} L_{n}=0
$$

Evaluate gain and update $\mathrm{L}$

$$
\begin{gathered}
K_{n+1}=R^{-1}\left(B^{T} P_{n}+L_{n}\right) C^{T}\left(C C^{T}\right)^{-1} \\
L_{n+1}=R K_{n+1} C-B^{T} P_{n}
\end{gathered}
$$

If $K_{n+1}$ and $K_{n}$ are close enough to each other, go to 3, otherwise set $n=n+1$ and go to 2 .

3) Terminate: Set $K=K_{n+1}$.

\section{Simulation Results}

Consider an MTLCD system shown in [22], [26]. The lumped mass of each structural level is from $131 T$ (top) to $338.6 T$ (bottom) and the damping ratio is assumed to be $3 \%$ in each mode. The natural frequencies are computed to be $0.23,0.35,0.42,0.49$ and $0.56 \mathrm{~Hz}$. The excitation acts at a frequency equal to the first natural frequency of the structure. The semiactive TLCD is placed on the top level with $\xi_{\text {max }}=15$. For simulation purpose, an exogenous disturbance input is set as:

$$
w(t)=a \cos (\omega t)+b \cos (2 \omega t)+c \cos (3 \omega t)+d \sin (4 \omega t)
$$

where $\omega=1.47 \mathrm{rad} / \mathrm{s}$ (equal to the first natural frequency of the structure), and the values of $a, b, c$ and $d$ and the stiffness matrix of the structure are given as follows:

$$
\begin{aligned}
& a=4.5 *[675.45,700.45,615.15,555.25,475.05]^{\mathrm{T}} k N \\
& b=4.5 *[0.3,375,284.5,175.3,15.1]^{\mathrm{T}} k N \\
& c=4.5^{*}[735.5,655.15,564.45,690.15,18.6]^{\mathrm{T}} k N \\
& d=4.5 *[180.5,35.5,425,280,650]^{\mathrm{T}} k N \\
& {\left[\begin{array}{cc}
K_{s} & 0 \\
0 & K_{f}
\end{array}\right]=177.2 *\left[\begin{array}{ccccc}
2000 & -1000 & 0 & 0 & 0 \\
-1000 & 4800 & -1400 & 0 & 0 \\
0 & -1400 & 6000 & -1600 & 0 \\
0 & 0 & -1600 & 6600 & 0 \\
0 & 0 & 0 & 0 & 7400
\end{array}\right] \mathrm{kN} / \mathrm{m}}
\end{aligned}
$$

Figure 2 shows the response of the top level of the tower under $H_{\infty}$ output feedback control methodology in the presence of the disturbance attenuation $\gamma=0.01$ and is compared to the uncontrolled case. Figure 3 indicates the profile of the variation in head loss coefficient $(\xi(t))$ as a function of time. Finally, the static $H_{\infty}$ control signal is 
plotted in Figure 4.

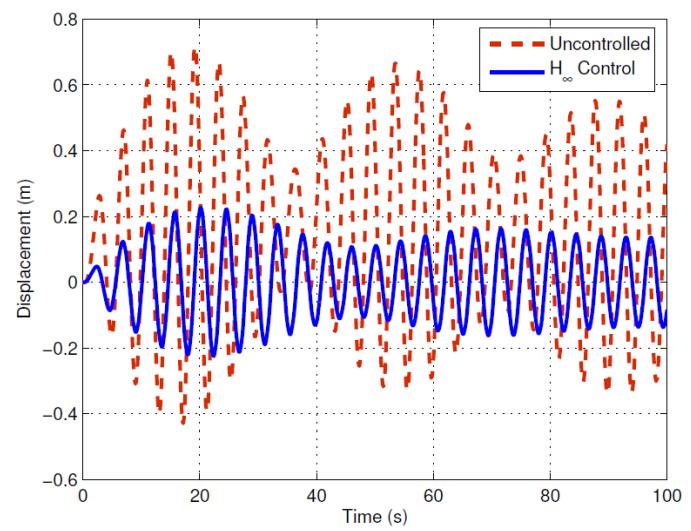

Fig. 2. Top displacement under $H_{\infty}$ output feedback control.

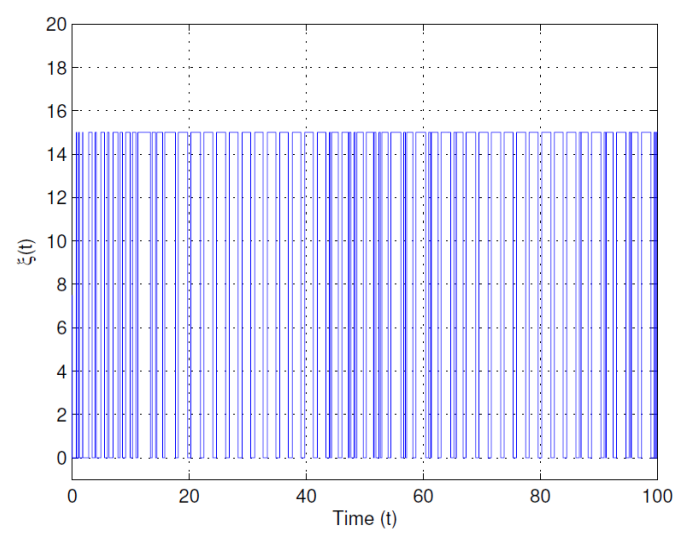

Fig. 3. Variation of head loss coefficient with time.

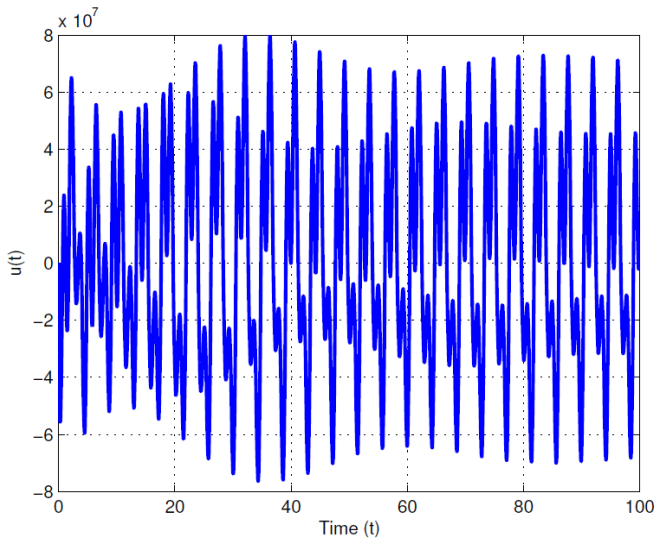

Fig. 4. $H_{\infty}$ control signal.

\section{Conclusions}

In this paper we propose an $H_{\infty}$ output feedback control methodology to reduce the vibrations in wind turbine structures. The vibrations have been mitigated by means of a tuned liquid column damper with a controllable valve. An $H_{\infty}$ static output feedback algorithm was proposed to solve the available Riccati equations. The explicit expression of the semiactive controllers was derived to satisfy both asymptotic stability and a prescribed level of disturbance attenuation.

\section{Acknowledgment}

This work has been partially funded by the Ministry of Science and Innovation of Spain through the coordinated research projects DPI2008 06699-C02-01 and by the Government of Catalonia through SGR523 and by the NORCOWE (Norwegian Centre for Offshore Wind Energy). M. Zapateiro is grateful to the grant of Juan de la Cierva program of the Ministry of Science and Innovation (Spain).

\section{References}

[1] W. Musial, S. Butterfield, Energy from offshore wind, Offshore Technology Conf., Houston, 2006.

[2] M. Kühn, Dynamics and design optimisation of offshore wind energy conversion system, $\mathrm{PhD}$ thesis, Delft University of Technology, 2001.

[3] K.E. Johnson, L.Y. Pao, M.J. Balas, L.J. Fingersh, Control of variable-speed wind turbines: standard and adaptive techniques for maximizing energy capture, IEEE Control Systems Magazine, 26(3), 70-81, 2006.

[4] B. Skaare, T. Hanson, F.G. Nielsen, Integrated dynamic analysis of floating offshore wind turbines, European Wind Energy Conf. \& Exhibition, Athens, Greece, 2006.

[5] B. Skaare, T. Hanson, F.G. Nielsen, Importance of control strategies on fatigue life of floating wind turbines, Int. Conf. Offshore Mechanics and Arctic Eng., 2007.

[6] M. Klose, P. Dalhoff, K. Argyriadis, Integrated load and strength analysis for offshore wind turbines with jacket structures, Int. Offshore and Polar Eng. Conf., 2007.

[7] N.J. Tarp-Johansen, Partial safety factors and characteristic values for combined extreme wind and wave load effects, J. Solar Energy Eng., 127, 242-252, 2005.

[8] J.M. Jonkman, Dynamics modeling and loads analysis of an offshore floating wind turbine, $\mathrm{PhD}$ thesis, University of Colorado, USA, 2007.

[9] A.W. Nielsen, E.A. Hansen, Time-varying wave and current-induced scour around offshore wind turbines, Int. Conf. Offshore Mechanics \& Arctic Eng., 2007.

[10] G. Bir, J. Jonkman, Aeroelastic instabilities of large offshore and onshore wind turbines, J. Physics: Conf. The Science of Making Torque from Wind, Copenhagen, Denmark, 75, 28-31, 2007.

[11] J. Van der Tempel, Design of support structures for offshore wind turbines, PhD thesis, Delft University of Technology, 2006.

[12] E.N. Wayman, P.D. Sclavounos, S. Butterfield, J. Jason, W. Musial, W., Coupled dynamic modelling of floating wind turbine systems, Offshore Technology Conf., 2006.

[13] H. Suzuki, A. Sato, Load on turbine blade induced by motion of floating platform and design requirement for the platform, Int. Conf. Offshore Mechanics \& Arctic Eng., 2007.

[14] S. Shim, M.H. Kim, Rotor-floater-tether coupled dynamic analysis of offshore floating wind turbines, Int. Offshore Polar Eng. Conf., Vancouver, 455-460, 2008.

[15] C.L. Bottasso (Ed.), Multibody dynamics - computational methods and applications, Computational Methods in Applied Sciences, Springer-Verlag, 2008.

[16] C.L. Bottasso, A. Croce, B. Savini, W. Sirchi, L. Trainelli, Aero-servo-elastic modeling and control of wind turbines using finite element multibody procedures, Multibody Systems Dynamics, 16, 291-308, 2006. 
[17] C.L. Bottasso, F. Campagnolo, A. Croce, M. Giuliani, Multi-disciplinary optimization of wind turbines using comprehensive aero-servo-elastic models, European and African Conf. on Wind Eng., Italy, 2009.

[18] G.S. Bir, C.L. Bottasso, A. Croce, L.C. Henriksen, Model updating of wind turbine blades using maximum likelihood constrained optimization, European Wind Energy Conf. \& Exhibition, Marseille, France, 2009.

[19] N. Luo, Semiactive control strategies for vibration reduction in smart structures, Advances in Control Systems Theory and Applications, 174-190, USTC Press, Hefei, China, 2009.

[20] C.L. Bottasso, A. Croce, B. Savini, W. Sirchi, L. Trainelli, Aeroelastic analysis and control of wind turbine generators, Eolica Expo Mediterranean, Roma, Italy, 2004.

[21] K. Sakai, S. Takaeda, T. Tamaki, Tuned liquid column damper - new type device for suppression of building vibrations, Int. Conf. Highrise Buildings, 1989.

[22] S.K. Yalla, A. Kareem, J.C. Kantor, Semi-active tuned liquid column dampers for vibration control of structures, Eng. Structures, 23, 1469-1479, 2001.

[23] S.D. Xue, J.M. Ko, Y.L. Xu, Tuned liquid column damper for suppressing pitching motion of structures, Eng. Structures, 23, 1538-1551, 2000.

[24] S. Colwell, B. Basu, Experimental and theoretical investigations of equivalent viscous damping of structures with TLCD for different fluids, J. Structural Eng., 134, 154-163, 2008.

[25] S. Colwell, B. Basu, Tuned liquid column dampers in offshore wind turbines for structural control, Eng. Structures, 31, 358-368, 2009.
[26] S.K. Yalla, A. Kareem, Optimum absorber parameters for tuned liquid column dampers, J. Structural Eng., 126, 906915, 2000.

[27] A.Y.J. Won, J.A. Pires, M.A. Haroun, Performance assessment of tuned liquid column dampers under random seismic loading, Int. J. Non-Linear Mechanics, 32(4), 745758, 1996;

[28] C.C. Chang , C.T. Hsu , S.M. Swei, Control of buildings using single and multiple tuned liquid column dampers. Structural Eng. \& Mechanics, 6, 77-93, 1998.

[29] H. Gao, K.S.C. Kwok , B. Samali, Characteristics of multiple tuned liquid column dampers in suppressing structural vibration, Eng. Structures, 21, 316-331, 1999.

[30] K.M. Shum, Y.L. Xu, Multiple-tuned liquid column dampers for torsional vibration control of structures: experimental investigation, Earthquake Eng. \& Structural Dynamics, 31, 977- 991, 2002.

[31] Z.G. Ying, Y.Q. Ni, J.M. Ko, Semi-active optimal control of linearized systems with multi-degree of freedom and application, J. Sound and Vibration, 279, 373-388, 2005.

[32] H.R. Karimi, M. Zapateiro, N. Luo, Vibration control of baseisolated structures using mixed $\mathrm{H}_{2} / \mathrm{H}_{\infty}$ output-feedback control, Proc. Institue of Mechanical Engineers Part I: Systems and Control Eng., 223, 809-820, 2009.

[33] M. Zapateiro, H.R. Karimi, N. Luo, B.F. Phillips, B.F. Spencer, A mixed $\mathrm{H}_{2} / \mathrm{H}_{\infty}$ - based semiactive control for vibration mitigation in flexible structures, IEEE Conf. Decision and Control, Shanghai, China, 2009. 